\title{
“Maio de 68", MOBILIZAÇÕES AMBIENTALISTAS E Sociologia AMBIENTAL
}

\section{Wilson José Ferreira de Oliveira ${ }^{1}$}

\begin{abstract}
RESUMO
A emergência de investigações sobre 0 ambientalismo está relacionada às mobilizações ocorridas no "maio de 68" e seus desdobramentos na Europa e nos EUA. Esse trabalho examina as relações entre 0 aparecimento de protestos e manifestações vinculadas ao maio de 68 , as principais mudanças teóricas e metodológicas que balizaram as investigações sobre as mobilizações ambientalistas e as condições intelectuais e institucionais de formação e de exercício das ciências sociais. Com base na comparação com a literatura internacional, demonstrase que a produção nacional tem se caracterizado pela grande quantidade de estudos de casos voltados para a avaliação dos "impactos sócio-ambientais" do desenvolvimento econômico e político e das estratégias alternativas representadas pelas mobilizações, bem como pela dificuldade de estabelecimento de pontos de partida teóricos e conceituais.

Palavras-chave: Movimentos Sociais. Tradições Intelectuais. Sociologia Ambiental.
\end{abstract}

\footnotetext{
${ }^{1}$ Prof. Adjunto do Departamento de Sociologia e Política da Universidade Federal de Pelotas e doutor em Antropologia Social pelo Programa de Pós-Graduação em Antropologia Social da Universidade Federal do Rio Grande do Sul. E-mails para contato: wilson@ufpel.tche.br ou mdwbg@pop.com.br.
} 


\begin{abstract}
The emergence of studies on environmentalism is related to the mobilizations that occurred in "May of 68" and their consequences in Europe and the U.S.A. This work examines the relationship between the rise of protests and demonstrations linked to May of 68 , the main theoretical and methodological changes that guided the studies on the environmental mobilizations and the intellectual and institutional conditions for the formation and exercise of the social sciences. Based on a comparison with the international literature, we demonstrate that the national production has been characterized by the large number of case studies focused on the evaluation of the "socio-environmental impacts" of economic and political development and on the alternative strategies represented by the mobilizations, as well as the difficulty of establishing theoretical and conceptual points of departure.
\end{abstract}

Keywords: Social Movements. Intellectual Traditions. Environmental Sociology.

\title{
INTRODUÇÃO
}

s manifestações e protestos transcorridos durante o "Maio de 68" nos EUA e
na Europa constituem um dos marcos principais do aparecimento de novas
formas de mobilização e de organização coletivas. Mesmo que as causas defendidas estivessem vinculadas a problemáticas e conflitos relativamente antigos, tais organizações se distinguiam das mobilizações até então existentes pela sua arquitetura organizacional, seus quadros ideológicos, seus repertórios de ação e a sua base social: descentralização e democracia interna, valores pós-materialistas, repertórios de ação moderada, membros da nova classe média (PASSY, 1998). É 0 caso de movimentos como o dos direitos humanos, o das mulheres, o pela paz, o contra a guerra do Vietnã, o estudantil, o antinuclear e o ecologista, entre outros. Assim sendo, as contestações estudantis das sociedades industriais pela juventude ocidental de "Maio de 68", ainda que não constituam uma influência isolada, têm sido consideradas como um dos principais ingredientes da emergência do movimento ecologista no início dos anos de 1970 (SPANOU, 1991). Isso se manifesta tanto em termos das vinculações políticas dos principais ativistas desse período ao "Maio de 68" quanto pelas formas de organização e referenciais ideológicos postos em prática pela "crítica ecologista" ou "ecologia política" ao sistema sócio-econômico e aos grandes aparelhos de dominação do mundo moderno (SIMONNET, 1979). 
Tais formas de mobilização e de protesto tiveram um forte impacto também sobre as abordagens então dominantes da ação coletiva e dos movimentos sociais nos EUA e na Europa (MEMMI, 1985; NEVEU, 1996; TONI, 2001). Ou seja, o aparecimento de mobilizações diferentes das operárias e sindicais, que tinham se fixado nas ciências sociais como uma espécie de "protótipo" para a maioria dos estudos, influenciou a emergência, ainda nos anos de 1970, das principais críticas e reformulações relacionadas a tais abordagens. Em consonância com a emergência de tais mobilizações e de suas influências sobre a reformulação da literatura acadêmica da ação coletiva e dos movimentos sociais, no início da década de 1970 surgiram diversos estudos das ciências sociais sobre os "problemas ambientais". Nesse sentido, pode-se tomar o "Maio de 68" como um marco da emergência tanto de mobilizações ambientalistas quanto da sociologia ambiental. Os impactos do "Maio de 68" sobre as lutas políticas e os movimentos sociais têm recebido, desde então, uma atenção destacada pela literatura pertinente. Todavia, ainda são poucos os trabalhos que salientam sua influência sobre a produção intelectual das ciências sociais relativa aos movimentos sociais e, mais especificamente, aos "problemas ambientais".

Sem pretender aqui dar conta das influências do "Maio de 68" sobre a produção intelectual referente aos "problemas ambientais", trata-se de salientar a pertinência do exame das relações entre as mobilizações e protestos ambientalistas e as redefinições teóricas e conceituais das investigações sobre tal temática. Semelhante ao que se tem observado no estudo dos movimentos sociais (GOHN, 1997), pretende-se demonstrar que a influência das mobilizações ecologistas sobre a produção intelectual ocorreu segundo condições particulares de configuração das ciências sociais em diferentes tradições intelectuais nacionais e dos respectivos problemas e debates teóricos e conceituais vinculados a tais contextos intelectuais. Desse modo, observa-se que as questões levantadas pela emergência dessas novas formas de ação coletiva na Europa e nos EUA foram "refratadas" (BOURDIEU, 1997) com base em divisões disciplinares e problemáticas teóricas e conceituais próprias às ciências sociais nessas respectivas tradições intelectuais. Esse é o caso do desenvolvimento das perspectivas "construtivistas" dos "problemas ambientais", decorrente dos debates sobre as "relações entre natureza e sociedade" como forma de explicação das causas estruturais da destruição ambiental, como também os estudos do engajamento individual no ativismo ambiental que resultou das discussões sobre a pertinência da posição de classe e das redes sociais nas investigações das condições e das dinâmicas de construção social de 
problemáticas, de mobilizações, de organizações e de atores vinculados à defesa de causas ambientais.

Em comparação com o observado nesses países, um dos aspectos que se destaca na produção intelectual brasileira, tanto sobre movimentos sociais quanto sobre a problemática ambiental, é seu aparecimento bem posterior à década de 1970, que foi o momento em que foram criadas as primeiras organizações ambientalistas (LOUREIR0 \& PACHEC0, 1995; OLIVEIRA, 2007). Essa resposta tardia da produção intelectual brasileira em relação à internacional resultou, primeiramente, de dinâmicas próprias vinculadas ao contexto político nacional. Isso porque, foi somente durante o ciclo de protesto decorrente do processo de "abertura política" e de "redemocratização", em meados da década de 1980, que surgiram novas formas de mobilização e de protestos coletivos. Desse modo, esse período é um marco do aumento expressivo das organizações e das mobilizações ecologistas, decorrente da maior articulação dos mais diferentes grupos e organizações sociais às lutas ambientais (ALONSO, COSTA \& MACIEL, 2007; OLIVEIRA, 2007). Tais mobilizações tiveram um papel preponderante para 0 engajamento dos intelectuais na realização de investigações sobre a problemática ambiental. Todavia, isso ocorreu de forma relativamente diferenciada do que se observou na Europa e nos EUA, devido às condições sociais de constituição e de exercício das ciências sociais no Brasil estarem diretamente imbricadas com 0 engajamento e a participação política (MICELI, 1989; PÉCAUT, 1990; MICELI, 1995). Em consonância com isso, tal contexto se caracterizou como um momento em que estava em jogo, para as camadas escolarizadas e intelectuais brasileiras, a afirmação e o exercício de seu papel de "ator político" pela inserção em manifestações da sociedade civil e por meio de estratégias voltadas para "fora" do meio intelectual, tais como os partidos políticos, os movimentos sociais e as classes populares (PÉCAUT, 1990). Com isso, as abordagens, as temáticas e os resultados das análises inicialmente propostas para o estudo da temática ambiental sofreram uma influência direta das preocupações e reivindicações das organizações e mobilizações ambientalistas, tornando-se fortemente "politizadas". Desse modo, a formulação de perspectivas teóricas e conceituais próprias e de sua vinculação com a produção internacional, bem como a constituição de uma agenda de pesquisas com problemas de pesquisa distintos dos debates e reivindicações políticas e ideológicas do ativismo ambiental, constitui, ainda hoje, um dos principais desafios encontrados na literatura brasileira sobre a temática ambiental (ALONSO \& COSTA, 2002b). 
Sem a mínima pretensão de esgotar o assunto, este artigo apresenta algumas considerações iniciais que evidenciam a pertinência do aprofundamento de investigações sobre as relações entre a trajetória diferenciada da sociologia ambiental em diferentes tradições intelectuais e as respectivas condições sociais e institucionais de formação e de exercício das ciências sociais. Para dar conta disso, o artigo está dividido em três seções principais. Em primeiro lugar, analisase o surgimento da temática ambiental na sociologia rural dos EUA e seus desdobramentos na constituição de uma sociologia ambiental "construtivista". Em seguida, examina-se a vinculação da sociologia ambiental com os estudos dos "novos movimentos sociais" na Europa e nos EUA e o debate relativo ao peso da posição de classe e das redes sociais nas dinâmicas de participação em mobilizações e organizações coletivas, bem como sua influência na constituição de perspectivas centradas nos processos de engajamento individual em causas coletivas. Em terceiro lugar, são apresentados os principais desenvolvimentos da sociologia ambiental brasileira e suas relações com a produção internacional. Por fim, a título de conclusão, salienta-se a pertinência de integrar às discussões sobre a sociologia ambiental uma sociologia das condições sociais e institucionais de exercício das ciências sociais.

\section{Sociologia Rural, “Crise Ambiental” e DinÂMicas InTERACionais de ConstruÇão de Causas Ambientais}

As tentativas de constituição de uma "sociologia ambiental" nos EUA durante os anos de 1970 foram inicialmente influenciadas pela emergência das mobilizações ambientalistas do final dos anos de 1960 e podem ser vistas como uma forma de importação de problemáticas políticas e ideológicas para o âmbito das ciências sociais. Nas palavras de Hannigan (1995, p. 23), tal formulação constituía "uma analogia acadêmica do pensamento dos 'verdes' em geral, defendendo uma abordagem que fosse menos 'antropocêntrica' (centrada no ser humano) e mais 'ecocêntrica' (os seres humanos são apenas uma das muitas espécies que habitam a Terra)". Tal proposta de "sociologia ambiental" emerge como um desdobramento da "sociologia rural" e se inscreve numa lógica de divisão e de demarcação de fronteiras disciplinares e institucionais frente às demais disciplinas vinculadas às ciências sociais e às principais escolas em confronto na sociologia dos EUA. Diante disso, tratava-se de estabelecer uma "nova área de especialização", diferenciada 
tanto das abordagens funcionalistas então dominantes, quanto das formulações interacionistas que se opunham as estas, além de se distinguir também da "ecologia humana" desenvolvida pela Escola de Chicago (FREUDENBURG \& GRAMILNG, 1989).

Uma das razões que contribuiu para tal formulação é que, até meados dos anos 1970, o termo "sociologia ambiental" era usado de forma bastante indiferenciada pelos sociólogos nos EUA, pois dizia respeito à utilização de abordagens vinculadas ao estudo dos movimentos sociais, da psicologia social, da opinião pública e dos problemas sociais, para a análise das problemáticas ambientais. A criação de uma nova especialidade que tomasse como objeto de estudo as relações de interação e de mútua dependência entre sociedade e ambiente foi uma iniciativa dos "sociólogos rurais" e contou, particularmente, com a liderança intelectual e institucional de Dunlap e Catton, bem como de Buttel. Primeiramente, oferecendo uma definição da "sociologia ambiental" que a distinguia deste conjunto heterogêneo de abordagens vinculadas aos estudos dos "problemas ambientais". Em segundo, ocupando posições de destaque em centros universitários, nas principais associações profissionais dos EUA (American Sociological Association, Society for the Study of Social Problems, Rural Sociological Society), na organização de numerosas sessões nos congressos profissionais, bem como no estabelecimento de "redes informais" de contato entre os "sociólogos ambientais" e aqueles não interessados prioritariamente nesta temática (FREUDENBURG \& GRAMILNG, 1989).

Tal proposta e seus desdobramentos iniciais centraram-se na análise das relações de influência recíproca e de mútua dependência funcional da "estrutura e mudança social" das sociedades humanas com o "ambiente biofísico" e as "variáveis ambientais" (ALONSO \& COSTA, 2002). Ela tinha como objetivo principal a explicação das causas da "destruição ambiental" e originou duas principais abordagens: a primeira, era a "explicação ecológica" que traçava um retrato da relação natureza-sociedade em termos das limitações e dos conflitos de funções que o meio ambiente oferece às sociedades humanas; e a segunda, a explicação da economia política que, inspirada nos trabalhos de Marx e Engels, atribuía "a culpa pela destruição do ambiente" ao capitalismo industrial e à sua sede de poder e lucro, focalizando as "relações contraditórias entre expansão econômica e destruição ambiental” (HANNIGAN, 1995, p. 32). Uma das principais críticas levantadas a tais abordagens é que elas aceitam como dado e sem críticas a existência de uma "crise ambiental" e explicam as mobilizações ambientalistas 
como um resultado e uma reação direta do grau de deterioração da natureza. Dessa forma, tal literatura tem sido contestada por ter adotado posturas normativas e valorativas que se expressam, entre outras coisas, pela sua preocupação em assegurar uma "futurologia ecologicamente segura" (HANNIGAN, 1995).

Em contraponto a tais posturas, constitui-se 0 que foi designado como uma abordagem "construtivista" dos "problemas ambientais", à qual toma como objeto de análise os processos pelos quais tais problemas são definidos, articulados e regulados pelos atores sociais. Conforme a abordagem construtivista, ao invés de adotar posturas normativas e valorativas a respeito das questões ambientais, tratava-se de apreender os "processos sociais, políticos e culturais através dos quais as condições ambientais são definidas como sendo inaceitavelmente arriscadas e, portanto, litigáveis" e de demonstrar que "os problemas e soluções ambientais são produtos finais de um processo de definição social, legitimação e negociação dinâmica, nas esferas pública e privada" (HANNIGAN, 1995, p. 44-45). Contrariamente às abordagens anteriores, bem como às perspectivas funcionalistas que postulavam que os problemas sociais eram produtos "diretos" e "necessários" de desordens funcionais e, portanto, de condições estruturais e objetivas claramente discerníveis, esta nova definição da "sociologia ambiental" constitui uma retomada e reformulação de certas vertentes vinculadas ao interacionismo simbólico que enfatizavam a "interação face a face" e as dinâmicas de "construção da ação", em função de processos interpretativos por parte dos atores no âmbito de situações sociais específicas. No âmbito do estudo dos problemas sociais, as análises interacionistas demonstravam a importância das "definições coletivas" para a constituição de uma determinada questão como uma causa legítima (BLUMER, 1971), aproximando-se daquelas perspectivas mais recentemente designadas de "pragmáticas", às quais tomam a "ação" dos atores sociais e o que eles "fazem" como ponto de partida para a investigação das condições, processos e práticas sociais (BÉNATOUÏL, 1999).

Ao deslocar o foco das investigações da dimensão objetiva dos "problemas ambientais" para a análise concreta dos processos sociais, políticos e culturais por meio dos quais certos aspectos da vida social são construídos como questões ambientais, tal abordagem demonstra que a relação natureza-sociedade é uma construção política e social que nem sempre corresponde diretamente à necessidade real ou objetiva do ambiente biofísico e sim aos valores e práticas dos atores sociais. Como salienta Lascoumes (1994, p. 9-10), o que designamos atualmente como "meio ambiente" não se reduz a um bem "pré-existente, nem um patrimônio 
a-histórico, nem uma entidade dotada de uma essência intemporal", pois se trata sempre de uma "natureza trabalhada pela política", de um "conjunto de elementos convertidos em recursos, trabalhados pela atividade humana, enfim, a resultante de empreendimentos conduzidos durante mais de vinte séculos, cujos objetivos são inseparavelmente de exploração, de valorização e de destruição". Desta forma, sem negar a dimensão objetiva dos "problemas ambientais", a abordagem "construtivista" passou a se concentrar nos processos pelos quais as questões ambientais são produzidas pela ação efetiva dos formuladores de exigências ambientais (cientistas, ambientalistas, autoridades, notabilidades, personalidades, a mídia, etc.), nas respectivas condições institucionais e organizacionais que respaldam sua ação, bem como nas capacidades e recursos por eles mobilizados nas dinâmicas de emergência, de legitimação e de contestação de "problemas ambientais". Nesse sentido, Hannigan (1995, p. 61) salienta que, ao se "procurar as origens das exigências ambientais, é importante para o investigador perguntar de onde é que vêm as exigências, a quem pertence ou quem lida com elas, que interesses econômicos e políticos os formuladores das exigências representam e que tipo de fontes eles trazem para o processo de criação das exigências".

As análises "construtivistas" têm se mostrado pertinentes para a elucidação e a comparação das condições e processos de emergênciae de proliferação de diversas organizações e grupos sociais participando das mobilizações ambientalistas em diferentes situações históricas e nacionais, focalizando os aspectos contextuais e multifacetados vinculados à recente difusão do ambientalismo para diversas categorias e setores sociais, sua imbricação com uma grande diversidade de questões sociais, bem como os conflitos vinculados ao sistema diversificado e heterogêneo de atores sociais e respectivos interesses e objetivos que os conduzem à participação na defesa das causas ambientais. Todavia, uma das dificuldades persistentes em tais análises diz respeito à investigação das condições de possibilidade e das dinâmicas sociais do engajamento individual nesses tipos de causas. Isso porque elas priorizam a investigação das dinâmicas interacionais entre as diversas organizações e atores envolvidos nas mobilizações, mas atribuem um lugar residual à influência das condições sociais de existência dos indivíduos sobre as probabilidades e as disposições para o engajamento, assim como dos diferentes processos de socialização e itinerários que os conduzem efetivamente à participação. A elaboração de novas alternativas para dar conta das condições e das lógicas sociais do engajamento individual em mobilizações ambientalistas e de suas vinculações com os processos de construção de causas 
ambientais resultou dos confrontos e do maior intercâmbio entre as abordagens européias e americanas sobre os chamados "Novos Movimentos Sociais", ou NMS, e das mudanças consideráveis que tal debate provocou em ambas: tanto nas que explicavam a participação nos movimentos com base na "origem de classe" de seus membros quanto nas que focalizavam os "laços anteriores" e as "redes sociais" que conduziam os indivíduos às ações coletivas.

\section{Sociologia dos Movimentos Sociais, Posição de Classe e Redes Sociais no Engajamento Individual EM Mobilizações AMbientalistas}

A temática dos movimentos sociais é bastante antiga nas ciências sociais e, em alguns momentos, chegou até a fazer parte dos manuais de teoria social dentro da problemática geral da "ação social" e mais especificamente da "ação coletiva". A primeira tentativa de definição "científica" de tal conceito tem como referência o trabalho de Lorenz Von Stein, de 1840, o qual defendia a importância de uma ciência da sociedade que tomasse como objeto de estudo os "movimentos sociais" que, naquele trabalho e nos estudos que os sucederam, eram identificados às lutas do operariado (SPANOU, 1991). Um segundo momento importante na produção sobre essa temática, foram os trabalhos vinculados ao interacionismo simbólico e à Escola de Chicago. Tal vertente chegou a ser denominada de "abordagem clássica”, estando centrada na problemática funcionalista que analisava sua emergência como um "fator de disfunção da ordem social" e que procurava compreender o comportamento coletivo dos grupos sociais por meio da análise de seus aspectos sócio-psicológicos e culturais (McADAM, 2003). Durante os anos 1950 na Europa, a abordagem marxista deu ao conceito um sentido bastante amplo focalizando por meio dele períodos históricos longos como o nacionalista, fascista, etc., e inserindo-o na problemática da "mudança e da transformação social" e numa perspectiva teleológica de que a classe trabalhadora seria o sujeito de tais mudanças (GOHN, 1997).

Foi somente com a emergência de mobilizações vinculadas ao "Maio de 68" e que eram diferentes das operárias e sindicais que tal situação começou a mudar, dando origem a reformulações consideráveis nas abordagens até então utilizadas. Nesse sentido, a literatura sobre os "Novos Movimentos Sociais", ou NMS, trouxe à tona reivindicações que resultavam na "politização" de esferas até então não definidas como "políticas" e que provocavam certa "extensão da 
política", no sentido de que doravante esta deveria abarcar "tanto os aspectos da vida privada quando os da vida pública". Foi como resultado da emergência destas "novas" formas de mobilização coletiva e de seu impacto sobre a literatura acadêmica que os estudos dos movimentos sociais começaram a se expandir (NEVEU, 1996). Nessas abordagens, as mobilizações ambientalistas constituíam um caso particular das dinâmicas dos NMS, e foi no âmbito dos debates e das reformulações teóricas e conceituas mais gerais sobre tais movimentos sociais que elas foram investigadas.

Quanto a isso, as análises européias, a partir de 1970, passaram a focalizar o problema das relações entre os novos valores, interesses e reivindicações defendidos pelos NMS e o "pertencimento de classe" de seus participantes e ativistas, em contraponto às abordagens centradas nas mobilizações operárias e sindicais. Uma das explicações que dominaram inicialmente tais estudos foi a chamada "tese da nova classe média". Segundo essa abordagem, as mobilizações e as demandas dos "NMS" eram consideradas como representativas, seja das "sociedades pósindustriais" ou "mais afluentes", seja das camadas médias de tais sociedades, no caso, os "especialistas sociais e culturais" (professores, trabalhadores sociais, médicos, jornalistas, artistas, etc.) (NEVEU, 1996). Em meio a uma grande variedade de posições teóricas e metodológicas, tais estudos têm colocado em pauta o problema das relações entre condição de classe, disposições individuais e dinâmicas de participação política (MEMMI, 1985). Admitindo que as classes sociais caracterizam-se pela sua multidimensionalidade, no sentido de que sua posição social, seus valores e práticas correspondentes não se definem unicamente pela vinculação com a esfera econômica, mas também política, social e cultural, diferentes abordagens têm salientado que as disposições individuais para a participação política estão estreitamente ligadas às desigualdades das condições sociais de origem e dos respectivos capitais (sociais, econômicos, políticos e culturais) possuídos pelos diferentes agentes sociais, devendo ser apreendidas em relação à posição e trajetória social dos militantes (BOURDIEU, 1997). No que pese a extensão dada ao conceito de "classe" e à sua pertinência na análise da participação política, um dos problemas que persiste nesse tipo de análise é a fixação nos determinantes de origem e de posição de classe e a dificuldade em integrar o problema da autonomia dos diversos contextos e situações sociais que decorrem da inscrição dos atores em múltiplos mundos sociais, na análise dos processos de socialização, de geração e de modificação das disposições que conduzem à participação nas mobilizações coletivas (FILLIEULE, 2001). 
Já nos EUA, a partir da década de 1970, as análises se concentraram na investigação da estrutura e dos recursos organizacionais que possibilitam 0 processo de mobilização para uma determinada causa e no estudo das condições "microestruturais" das dinâmicas de participação, focalizando os vínculos anteriores e/ou simultâneas dos militantes com organizações e atores políticos. Tratava-se, com isso, de identificar os diferentes "mecanismos e concatenados processos" que configuram as dinâmicas de participação em mobilizações coletivas, ao invés de se contentar com a utilização de modelos estruturais estáticos e abstratos ou com explicações que consideram a participação como algo que acontece de forma mecânica e automática em decorrência dos objetivos e da ideologia do movimento, de certas "disposições psicológicas" presentes nos indivíduos ou de seu "pertencimento de classe". Nesse sentido, sem ignorar as "disposições psicológicas", Snow e Ekland-0lson (1980) salientaram a importância dos "laços interpessoais" e das "redes pré-existentes" para o recrutamento dos ativistas, demonstrando que são as variações nessas "redes interpessoais" que conduzem ao recrutamento diferencial dos integrantes dos movimentos sociais. Desse modo, indivíduos com condições favoráveis à participação, como grande disponibilidade ocupacional e de tempo, ausência de compromissos e de compensações inibitórias (riscos e sanções externas), somente se engajam quando tais condições aparecem associadas à existência de laços interpessoais e de vínculos com participantes do movimento.

Tais abordagens possibilitaram explorar de outra forma o problema da escolha e das motivações que conduzem ao engajamento individual. Sejam elas informais (conhecimentos e amizades) ou formais (visita à sede da organização, contato com a mobilização em jornais, vínculos com organizações ligadas ao movimento, ter visto pôsteres e banners, etc.), as redes sociais constituem uma das condições necessárias para o despertar da motivação para participar, ou mais precisamente, para a percepção individual dos custos e benefícios obtidos com a participação. Como demonstram Klandermans \& Oegema (1987), a importância de características como alto nível de educação e de profissão nas análises do movimento pacifista, resulta simplesmente delas conectarem os indivíduos com "redes sociais engajadas no recrutamento". Além disso, a vinculação anterior a redes sociais tem um papel destacado na conformação das concepções de mundo que conduzem ao engajamento em tais movimentos, constituindo-se num espaço prévio de socialização, de formação das identidades e de aproximação das principais lideranças, organizações e princípios ideológicos defendidos. Como mostram 
McAdam \& Paulsen (1993), o processo de engajamento resulta da interdependência entre a inserção em redes formais ou informais e a identificação subjetiva com uma particular identidade, de modo que isoladamente eles não são suficientes para que a decisão de participar ocorra. Segundo os referidos autores, os laços anteriores com organizações ou indivíduos somente encorajam o ativismo quando reforçam a identificação do potencial recruta com uma particular identidade e ajudam a estabelecer uma forte ligação entre tal identidade e o respectivo movimento. Para responder a tal questão, eles utilizam a noção de "identidade saliente", pois esta define as "identidades" como "sendo organizadas dentro de uma hierarquia de saliência definida pela probabilidade das várias identidades serem invocadas em uma dada situação ou em muitas situações" e atribui certa "centralidade e importância de nossos relacionamentos com outros" para estabelecer e sustentar a saliência de determinada identidade (McADAM \& PAULSEN, 1993, p. 647).

No que pese a pertinência dos elementos destacados por tais abordagens, as dificuldades que elas enfrentam são praticamente opostas às que se encontravam nas análises anteriores, pois a análise das redes pré-existentes não esteve integrada à investigação dos determinantes de origem e de posição de classe dos ativistas e de suas influências sobre a constituição das disposições propícias à participação política e sobre as dinâmicas de socialização anteriores ou simultâneas em outros tipos de mobilizações. Assim, elas tratam as disposições que conduzem ao engajamento como sinônimo de identidade e como resultado das próprias dinâmicas da interação, reduzindo o ator e a ação ao que Lahire (2002, p. 46-7) chama de "lógica da situação presente", pois negligencia o "passado dos atores" e a "seqüência da ação considerada", tratando-se sempre de "atores desprovidos de passado, obrigados apenas pela lógica da situação presente", de modo que 0 interesse da investigação se centra na "ação per se (seus contextos, seu curso, suas modalidades, sua gramática), seja qual for o passado do ator que a efetua". Desse modo, pode-se dizer que as tentativas de reintegrar a racionalidade do ator pela recusa das abordagens psicológica e individualista deparam-se com certas dificuldades quanto à própria possibilidade de pensar os processos de socialização anteriores à interação.

Até a década de 1980, tais abordagens eram marcadamente nacionais e mantinham uma relativa ignorância quanto às pesquisas e casos privilegiados nos diferentes países do mundo ocidental. Todavia, durante os anos de 1990, ocorreu um crescente intercâmbio e trocas entre tais pesquisadores, tornando-se difícil, depois disso, demarcar distinções entre abordagens européias e norte-americanas 
ou entre tradições nacionais. Paralela à ruptura com o "provincianismo teórico", há uma tendência no sentido de adoção de análises comparativas com o intuito de conseguir distinguir semelhanças e regularidades das diferenças e particularidades próprias das diversas realidades nacionais onde tais movimentos podiam ser observados (McADAM, McCARTHY \& ZALD, 1996). 0 maior intercâmbio dos desafios e alternativas propostos pela literatura internacional tem gerado um esforço crescente no sentido de se evidenciar as vinculações entre as abordagens que focalizam a "constituição e posição social" dos militantes e as que se centram nas "dinâmicas interacionais e nas lógicas processuais" que os conduzem ao engajamento individual, enfatizando as diversas redes de inserção dos militantes no decorrer de suas trajetórias sociais, escolares, militantes e profissionais (AGRIKOLIANSKY, 2002; COLLOVALD et alli., 2002; DIANI \& McADAM, 2003; SIMÉANT, 2005). A "redescoberta" e utilização da noção de "carreira" para a análise do militantismo está diretamente vinculada a esses confrontos teóricos e à busca de alternativas conceituais e metodológicas para a integração da perspectiva diacrônica na investigação dos processos de socialização que conduzem à participação em organizações e mobilizações coletivas. Ela pretende dar conta tanto de um "modelo processual ou seqüencial da ação militante" quanto considerar a "constelação de fatores" que concretamente tornam possível a participação, ao invés de reduzi-la ao reflexo de normas, papéis e constrangimentos estruturais (FILLIEULE, 2001).

Em consonância com isso, tem-se observado uma grande expansão dos estudos sobre diferentes tempos e locais na configuração de formas diversificadas de participação na defesa de causas ambientais e a renovação da agenda de pesquisa sobre 0 engajamento individual em mobilizações e organizações ambientalistas. Nesse sentido, um conjunto diversificado de pesquisas tem salientado a importância das dinâmicas processuais e seqüenciais da ação militante e da diversidade de recursos socais que concretamente torna possível tanto a participação em mobilizações ambientalistas (OLLITRAULT, 1996, 1999, 2001; SAINTENY, 1999, 2000; SAWICKI 2002) quanto as intervenções dos ativistas em instâncias formais de proteção ambiental (LASCOUMES 1994; ANQUENTIN 2002; GALLET 2002). Além disso, análises comparativas dos processos e das modalidades de constituição da luta ambiental em diferentes países e épocas têm demonstrado que as dinâmicas de institucionalização do ambientalismo na Europa Ocidental, nos Estados Unidos e no Terceiro Mundo são bastante diferenciadas conforme as configurações das redes formais e informais que convergem para as organizações e mobilizações 
ambientalistas (ROOTES, 1999), bem como dos tipos de recursos acumulados pelos ativistas no decorrer de seus trajetos familiares, escolares, políticos e profissionais (DEVAUX, 2005).

\section{“REDEMOCRATIZAÇÃo”, Movimento Ecológico E os “Impactos Sócio-Ambientais" do DESENVOLVIMENTO}

Dentro desse quadro geral de desenvolvimento da produção teórica das ciências sociais sobre a temática dos movimentos sociais e das mobilizações ambientalistas, a produção brasileira apresenta algumas particularidades que precisam ser consideradas com mais atenção, na medida em que isso influenciou a grande maioria dos estudos realizados no Brasil. Diferente do que ocorreu nos EUA e na Europa, onde a produção acadêmica sobre o fenômeno ambientalista emergiu num contexto muito próximo ao de surgimento do movimento ecológico, no caso brasileiro isso ocorreu quase uma década depois. 0 processo de redemocratização teve um papel destacado para a expansão do movimento ambientalista, na medida em que possibilitou a associação das questões ambientais com as problemáticas políticas e ideológicas que também estavam na agenda de outras organizações. Tal período se caracterizou também pelo retorno de antigos militantes e intelectuais que se opunham ao regime militar e que, no exílio, converteram-se ao ambientalismo. Foram eles que elaboraram os primeiros trabalhos sobre a questão ambiental no Brasil, de modo que foi a partir do contato com os movimentos ambientalistas europeus e da apropriação militante, por parte dos principais fundadores do ambientalismo brasileiro, que são incorporados certas abordagens que estavam sendo elaboradas para dar conta do ativismo ambientalista naquelas situações, como é o caso das análises centradas nas categorias dos "Novos Movimentos Sociais".

Um dos principais aspectos que chama a atenção, nesse caso, éa inexistência de formulações teórico-metodológicas próprias, elaboradas com base no exame das especificidades históricas, políticas e culturais da sociedade brasileira e das modalidades de movimentos sociais que emergiram em tais condições. Quanto a isso, vale a pena citar a observação de Gohn (1997, p. 13-14), quando ela salienta que nessa situação e na América Latina como um todo, "as posturas metodológicas foram híbridas, geraram muitas informações, mas o conhecimento produzido foi orientado basicamente pelas teorias criadas em outros contextos, diferente de suas realidades nacionais". A autora destaca também que o paradigma que 
serviu de base para a análise dos "dados da realidade", produzidos a partir de uma grande quantidade de estudos empíricos e descritivos pouco analíticos e "centrados nas falas dos agentes", foram as diversas orientações teóricas e metodológicas européias, incorporadas aos estudos de modo "acrítico" na medida em que se tratava da utilização de "categorias que se opõem no debate teórico" e à margem do debate dos europeus com o paradigma norte-americano nos anos 1980. Em decorrência disso, a literatura brasileira se caracteriza pela ausência de pontos de partidas teóricos e conceituais, constituindo-se como uma produção em que os estudos são empíricos e descritivos, utilizando-se de forma não-crítica os paradigmas europeus, fundamentalmente o dos "Novos Movimentos Sociais" (GOHN, 1997, p. 10).

Desse modo, o interesse pela investigação da participação nesse tipo de causa não resultou do confronto entre paradigmas e correntes analíticas próprias e concorrentes, sendo antes orientada pelo que foi produzido em outros contextos a partir do "comprometimento político" que, como demonstra Pécaut (1990), tomou conta da cultura universitária e profissional na sociedade brasileira durante a redemocratização. Segundo ele, trata-se de um momento em que estava em jogo, também para as camadas escolarizadas e intelectuais, a afirmação e o exercício de seu papel de "ator político": "participando integralmente das interações com outros atores políticos, sem ignorar as reivindicações corporativistas, mas inserindo-as no conjunto das manifestações da sociedade civil" por meio de estratégias voltadas para fora do meio intelectual "para os partidos políticos, os movimentos sociais e as classes populares" (PÉCAUT, 1990, p. 300). Nesse contexto de forte imbricação das ciências sociais com a militância em partidos políticos, organizações e movimentos sociais, as abordagens e os tipos de problemáticas que orientavam os estudos sobre as mobilizações ambientalistas estavam diretamente associados com as preocupações, problemas e reivindicações levantadas pelas lideranças e organizações que faziam parte de tais movimentos.

É dessa forma que a importação do modelo dos "Novos Movimentos Sociais" tornou-se uma constante também nos estudos das mobilizações ambientalistas no Brasil. A vinculação dos valores e das reivindicações defendidas pelas organizações ambientalistas ao pertencimento de classe dos seus membros tornou-se uma das abordagens predominantes em tais estudos, definindo os militantes das lutas ambientaiscomomembrosdachamada "classemédiaintelectualizada" ederivando disso a explicação de suas particularidades em termos de formulações identitárias, assim como de suas estruturas políticas e organizacionais (TORNQUIST, 1992; 
SCHMITT, 1995). Com base nisso, tais causas são caracterizadas como portadoras de reivindicações "novas" e "pós-materialistas", e procura-se compreender as dificuldades de articulação e de alianças entre as principais associações ambientalistas, assim como as concepções e os valores que os dirigentes de organizações atribuem à participação na defesa das causas ambientais. Nos últimos anos, os estudos sobre o movimento ecológico praticamente desapareceram. Como salientam Alonso e Costa (2002), a partir de finais da década de 1980, os estudos mantiveram o "viés político, engajado", concentrando-se no "desenvolvimento sustentável". Com isso, a categoria "movimento ecológico" foi praticamente abandonada pela literatura, passando-se a privilegiar os estudos dos processos de "degradação ambiental", o que conduziu à multiplicação dos estudos sobre os "impactos sócio-ambientais" do desenvolvimento econômico e político e sobre as "estratégias alternativas" representadas pelas mobilizações ambientalistas (LOUREIRO \& PACHECO, 1995). Mesmo quando focaliza as limitações políticas e institucionais dos mecanismos participativos e deliberativos em matéria de proteção ambiental, tais abordagens se caracterizam pela predominância de um forte engajamento e comprometimento com as causas ambientais e com os modelos de "desenvolvimento sustentável", deixando de lado a investigação empírica das condições sociais, políticas e institucionais de funcionamento concreto das instâncias de formulação e implementação de políticas ambientais (ALONSO \& COSTA, 2002). Nesse sentido, tem sido destacado que a rotinização e institucionalização dos procedimentos e a concentração dos processos decisórios nas mãos de poucos especialistas que detêm os conhecimentos técnicos, jurídicos e científicos requeridos, constituem os principais fatores responsáveis pela falta de incorporação da "participação democrática e igualitária" nos processos de formulação e implementação de políticas ambientais (LEITE LOPES, 2004; ZHOURI, LASCHEFSKI, PEREIRA, 2005).

Dessemodo, oexamedaliteraturanacional sobreos "problemas ambientais" tem nos colocado diante de uma situação de forte imbricação entre as abordagens científicas e o debate político, ao invés da consolidação de um "campo" próprio de estudos e pesquisas ou até mesmo de uma agenda de pesquisa com perspectivas teóricas e conceituais e problemáticas de investigação distintas das preocupações políticas e ideológicas do movimento ambientalista. Semelhantemente ao que tem sido observado em outras situações nacionais (DEVAUX, 2005), no caso do Brasil é tal imbricação e a própria ausência do militantismo ambientalista como objeto de estudo que se apresenta como um dos principais problemas de investigação. 
Mais do que lamentar essa carência de formulações teóricas e conceituais e de problemas de pesquisa próprios sobre o militantismo ambientalista, o desafio que enfrentamos é de tomá-la como objeto de análise com o intuito de apreender suas relações com determinadas condições intelectuais e institucionais de formação e de exercício das ciências sociais no Brasil. Uma das principais hipóteses que tem se mostrado pertinente para a compreensão disso diz respeito à própria dinâmica de emergência e de expansão da formação universitária e profissional no Brasil como indissociáveis do engajamento e da participação política (DEZALAY \& GARTH, 2002; CORADINI, 1998; PÉCAUT, 1990), como também, à intensificação, nos últimos anos, de sua utilização instrumental como instrumento de politização para a atuação profissional em diferentes esferas de atividade (CORADINI, 2002). Nesse sentido, pode-se dizer que as mudanças de abordagem no estudo do ambientalismo expressam, por um lado, uma dinâmica própria de expansão do ensino universitário ocorrido no Brasil durante os últimos anos no sentido da intensificação da imbricação entre formação escolar e universitária com engajamento político e, por outro, à própria configuração do ambientalismo como uma esfera de reconversão profissional das mais diversas "especialidades" para a atuação em diferentes esferas sociais (OLIVEIRA, 2005). Com isso, a inserção da temática ambiental no espaço da academia constitui atualmente uma das formas de articulação da universidade e dos tipos diversificados de formação que ela oferece com a inserção de estudantes, professores e pesquisadores em diversas redes de organização e movimentos sociais, demonstrando uma forte vinculação a concepções de sociedade e de política segundo as quais o valor e a utilidade da formação escolar e profissional resultam da possibilidade de sua utilização instrumental para a "politização" de diferentes esferas de atuação.

\section{Conclusões}

Como este artigo procurou demonstrar, o surgimento de mobilizações coletivas vinculadas ao movimento de contestação de "Maio de 68" constitui um dos marcos principais do engajamento das ciências sociais na investigação da problemática ambiental. Tal aspecto já tem sido admitido por alguns trabalhos que tratam da sociologia ambiental (HANNIGAN, 1995; COSTA FERREIRA, 2004). Todavia, ainda são poucos os que procuram evidenciar como a relação entre tais mobilizações e sociologia ambiental toma conotações diferenciadas conforme as particularidades históricas das próprias mobilizações e protestos, bem como 
segundo as especificidades das condições sociais, institucionais e intelectuais de configuração das ciências sociais.

Nesse sentido, essa breve reconstituição do impacto das mobilizações e ações coletivas sobre as ciências sociais nas diferentes tradições intelectuais consideradas nos coloca diante de um conjunto distinto de formulações teóricas e conceituais e de problemáticas de investigação para o estudo sociológico da questão ambiental. Tais variações resultam, por um lado, de diferenças quanto aos tipos de mobilizações coletivas que influenciaram a emergência da temática ambiental como objeto de estudo das ciências sociais nesses diferentes contextos intelectuais. É o caso das mobilizações de "Maio de 68" na Europa e nos EUA e das mobilizações vinculadas à luta pela "redemocratização" no Brasil. As questões e reivindicações que estavam em jogo em tais mobilizações não eram as mesmas, pois se tratava de contextos políticos bastante diferenciados. Por outro lado, as diferenças quanto aos tipos de protestos e reivindicações não parecem suficientes para a compreensão das variações quanto aos tipos de problemas e de perspectivas teóricas e conceituais vinculadas à sociologia ambiental nessas tradições intelectuais. Para dar conta disso, devem-se levar em conta também as relações estabelecidas entre os debates "internos" às ciências sociais e as demandas "externas" vinculadas a confrontos políticos e ideológicos. Nesse sentido, as tradições européias e norte-americanas parecem corresponder a situações em que as questões levantadas a partir da emergência de tais formas de mobilização foram "retraduzidas" (BOURDIEU, 1997) para o universo das ciências sociais com base em formulações e problemas de pesquisa próprios a cada campo intelectual.

0 caso brasileiro ilustra uma trajetória intelectual relativamente diferenciada de configuração da sociologia ambiental, pois nesse caso o impacto das mobilizações pela "redemocratização" resultou numa forte imbricação entre as abordagens científicas e o debate político sobre o ambientalismo, ao invés da consolidação de um campo de estudos e pesquisas com problemáticas teóricas e conceituais próprias das ciências sociais. Desse modo, a superação de tal situação e a elaboração de uma agenda de pesquisa com problemas distintos das preocupações políticas e ideológicas do movimento ambientalista constitui, ainda hoje, um dos principais desafios na constituição de bases teóricas e conceituais para uma sociologia ambiental que dê conta das particularidades do ambientalismo no Brasil (ALONSO \& COSTA, 2002b). Examinar o desenvolvimento da produção nacional sobre os "problemas ambientais" de forma integrada a uma sociologia das condições sociais e institucionais de exercício das ciências sociais constitui uma das alternativas para superar tal situação. 


\section{REFERÊNCIAS}

AGRIKOLIANSKY, Eric. La Ligue Française des Droits de L'Homme et du Citoyen Depuis 1945. Paris: L'Harmattan, 2002.

ALONSO, Ângela e COSTA, Valeriano. Ciências Sociais e Meio Ambiente no Brasil: um balanço bibliográfico. Boletim Informativo Bibliográfico, ANPOCS, n. 53, São Paulo, 2002, p.35-78.

. Por uma Sociologia dos Conflitos Ambientais no Brasil. In : ALIMONDA, Héctor. Ecología Política. Naturaleza, sociedad y utopía. Buenos Aires: CLACSO, 2002b, p. 115-135.

ALONSO, Ângela, COSTA, Valeriano e MACIEL, Débora Alves. 0 Processo de Formação da Rede de Ativismo Ambientalista no Brasil. XIII Congresso Brasileiro de Sociologia. Recife, 29 de maio a 06 de junho de 2007.

ANQUENTIN, Virginie. Produire une Politique Municipale de l'Environnement: La regulation des interactions des acteurs locaux par l'expertise. In: HAMMAN, Philippe, MEON, Jean-Matthieu, VERRIER, Benoît. (orgs.). Discours Savants, Discours Militants: mélange des genres. Paris: L'Harmattan, 2002, p. 129-151.

BÉNATOUÏL, Thomas. Critique et Pragmatique en Sociologie: Quelques Príncipes de Lecture. Annales - Histoire, Sciences Sociales, (2). Paris, mars/avril, 1999, p. 281-317.

BLUMER, Hebert. Social Problems as Collective Behavior". Social Problems, XVIII, n. 3, 1971, p. 298-306.

BOURDIEU, Pierre. La Distinction : critique sociale du jugement. Paris: Minuit, 1979 .

. Les Usages Sociaux de la Science: pour une sociologie clinique du champ scientifique. Paris: INRA, 1997.

COLLOVALD, Anne. Introduction. In : COLLOVALD, Anne ; LECHIEN, Marie-Hélène; ROZIER, Sabine\& WILLEMZ, Laurent. (orgs.). L'Humanitaire ou le Management des Dévouements : enquête sur un militantisme de "solidarité internationale" en faveur du tiers-monde. Rennes: PUR, 2002, p. 7-18.

CORADINI, Odaci Luiz. Panteões, Iconoclastas e as Ciências Sociais. In: FELIX, Loiva Otero \& ELMIR, Cláudio Pereira. (orgs.) Mitos e Heróis: construção de imaginários. Porto Alegre: EdUFRGS, 1998, p. 209-235. 
. Escolarização, Militantismo e Mecanismos de "Participação Política". In: HEREDIA, Beatriz, TEIXEIRA, Carla, BARREIRA, Irlys. (orgs.). Como se fazem eleições no Brasil. Rio de Janeiro: Relume-Dumará, 2002, p. 153.

COSTA FERREIRA, Leila da. Idéias para uma Sociologia da Questão Ambiental - teoria social, sociologia ambiental e interdisciplinaridade. Desenvolvimento e Meio Ambiente, n. 10, jul/dez, 2004, p. 77-89.

DEVAUX, Sandrine. Les Nouveaux Militantismes dans l'Europe Élargie. Paris: L'Harmattan, 2005.

FILLIEULE, Olivier. Propositions Pour Une Analyse Processuelle de l'Engagement Individuel. Revue Francaise de Science Politique, Vol 51, n. 1-2, février-avril, 2001, p. 199-215.

FREUDENBURG, William R. \& GRAMILNG, Robert. The Emergence of Environmental Sociology: Contributions of Riley E, Dunlap and William R. Catton, Jr. Sociological Inquiry, vol 59, n. 4, november, 1989, p. 439-452

GALLET, Gérald. L'Expertise, Outil del'Activisme Environnemental Chez Greenpeace France. In: HAMMAN, Philippe, MÉON, Jean-Mathieu e VERRIER, Benoît. Discours Savants, Discours Militants: mélange des genres. Paris: L'Harmattan, 2002, p. 109-128.

GOHN, Maria da Glória. Teoria dos Movimentos Sociais: paradigmas clássicos e contemporâneos. São Paulo: Loyola, 1997.

HANNIGAN, John. A. Sociologia Ambiental: a formação de uma perspectiva social. Lisboa: Instituto Piaget, 1995.

KLANDERMANS, Bert, OEGEMA, Dirk. Potentials, Networks, Motivations, and Barriers: steps towards participation in social movements. American Sociologial Review, vol. 52, n. 4, august 1987, p. 519-531.

LAHIRE, Bernard. Homem Plural: os determinantes da ação. Petrópolis: Vozes, 2002.

LASCOUMES, Pierre. L'Éco-Pouvoir: environnements et politiques. Paris: La Découverte, 1994.

LEITE LOPES, José. S. A Ambientalização dos Conflitos Sociais: Participação e Controle Público da Poluição Industrial. Rio de Janeiro: Relume-Dumará, 2004.

LOUREIRO, Maria Rita e PACHECO, Regina Silva. Formação e Consolidação do Campo Ambiental no Brasil: Consensos e disputas (1972-1992)" Revista de Administração Pública, vol 29, n. 4, Rio de Janeiro, out/dez, 1995, p. 137-153. 
McADAM, Doug, McCARTHY, John D., ZALD, Mayer N. (eds.) Comparative Perspectives on Social Movements: political opportunities, mobilizing estructures and cultural framings. Cambridge/New York: Cambridge University Press, 1996.

McADAM, Doug. Beyond Structural Analysys: Toward a more dynamic understanding of social movements. In: DIANI, Mario and McADAM, Doug. (Eds.) Social Movements and Networks. relational approaches to collective action. New York: Oxford University Press, 2003, p. 281-298.

MICELI, Sérgio. (org.). História das Ciências Sociais no Brasil (vol. 1). São Paulo: Vértice, 1989.

(org.). História das Ciências Sociais no Brasil (vol. 2). São Paulo: Sumaré/FAPESP, 1995.

MEMMI, Dominique. L'Engagement Politique. In: GRAWITZ, Madeleine. \& LECA, Jean. Traité de Science Politique, (vol 3) L'Action Politique. Paris: PUF, 1985, p. 310-366.

NÉVEU, Erik. Sociologie des Mouvements Sociaux. Paris: La Découverte, 1996.

OLLITRAULT, Sylvie. De la Caméra à la Pétition-web: le répretoire médiatique des écologistes. In: NEVEU, E. (Dir.). Médias et Mouvements Sociaux. Reseaux, n. 98, Paris, Hermès Science Publications, 1999, p. 153-185.

Les Écologistes Français, des Experts em Action. Revue Francaise de Science Politique, Vol 51, n. 1-2, février-avril, 2001, p. 105-130.

. Science et Militantisme: les transformations d'une échange circulaire : Le cas de l'ecologie française. Politix, n. 36, 1996, p. 141-162.

OLIVEIRA, Wilson J. Ferreira. Gênese e Redefinição da Causa Ambiental no Brasil. In: VII Reunião de Antropologia do Mercosul: Desafios Antropológicos. Porto Alegre: Associação Brasileira de Antropologia/UFRGS, 2007, v. 1. p. 1-20.

Paixão pela Natureza: Atuação Profissional e Participação na Defesa de Causas Ambientais no Rio Grande do Sul entre 1970 e Início dos Anos 2000. Tese (Doutorado em Antropologia Social) - Departamento de Antropologia. Porto Alegre: UFRGS, 2005. Disponível em: http://www.bibliotecadigital.ufrgs.br/da.php $? \mathrm{nrb}=000526042 \& \mathrm{loc}=2006 \& 1=$ bf2bb6bbdcf3022e [acesso em 2 de setembro de 2007].

PASSY, Florence. L'Action Altruiste. Paris-Genève: Droz, 1998.

PÉCAUT, Daniel. Os Intelectuais e a Política no Brasil: Entre o povo e a nação. São Paulo: Ática, 1990. 
R00TES, Christopher. (ed.) Environnmental Movements: local, national and global. London: Frank Cass, 1999.

SAINTENY, Guilhaume. Logiques d'Engagement et Logiques de Rétribution au Sein de l'Écologisme Français. Cahiers Internationaux de Sociologie, Vol CVI, 1999, p. 175-200.

SAINTENY, Guilhaume. L'Introuvable Écologisme Français? Paris: PUF, 2000.

SAWICKI, Fredéric. Les Temps de l'Engagement. À propôs de l'Institutionnalisation d'une association de Défens de l'Environnnement. In: LAGROYE, Jacques (org.). La Politisation. Paris: Belin, 2003, p. 123-146.

SCHMITT, Cláudia. Job. Mata de Araucárias: a região norte do Rio Grande do Sul. In: CARVALHO, Isabel Cristina de Moura e SCOTTO, Gabriela.. (coords.) Conflitos Sócio-Ambientais no Brasil. Rio de Janeiro: Graphos, 1995, p. 25-101.

SIMÉANT, Johanna, DAUVIN, Pascal. \& C.A.H.I.E.R. Le Travail Humanitaire: les acteurs des ONG, du siege au terrain. Paris: Presses de Sciences Po, 2002.

SIMMONET, Dominique. O ecologismo. Lisboa: Moraes Editores, 1979.

SPANOU, Calliope. Fonctionaires et Militants: l'administration et lês nouveaux mouvements sociaux. Paris: l'Harmattan, 1991.

TONI, F. Novos Rumos e Possibilidades para os Estudos dos Movimentos Sociais. $B I B$, n. 52, São Paulo, $2^{\circ}$ Semestre de 2001, p. 79-104.

TORNQUIST, Carmen Susana. O Planeta e o Quintal: o movimento ecológico frente à administração popular em Porto Alegre. Dissertação (mestrado em Sociologia Política). Universidade Federal de Santa Catarina. Florianópolis: UFSC/ PPGSOCPOL, 1992.

ZHOURI, Andréa; LASCHEFSKY, Klaus; PEREIRA, Doralice. B. A Instutentável Leveza da Política Ambiental: desenvolvimento e conflitos sócioambientais. Belo Horizonte: Autêntica, 2005. 